NBER WORKING PAPER SERIES

\title{
A NEW MODEL OF QUALITY
}

Kala Krishna

Tor Winston

Working Paper 6580

http://www.nber.org/papers/w6580

\section{NATIONAL BUREAU OF ECONOMIC RESEARCH 1050 Massachusetts Avenue \\ Cambridge, MA 02138 \\ May 1998}

Kala Krishna gratefully acknowledges the financial support from the National Science Foundation, grant SBR-9320825. The authors are grateful to Kalyan Chaterjee, Marie Thursby, Laura Bevins, and Eric Bond for comments. Any opinions expressed are those of the authors and not those of the National Bureau of Economic Research.

(C) 1998 by Kala Krishna and Tor Winston. All rights reserved. Short sections of text, not to exceed two paragraphs, may be quoted without explicit permission provided that full credit, including (C) notice, is given to the source. 
A New Model of Quality

Kala Krishna and Tor Winston

NBER Working Paper No. 6580

May 1998

JEL Nos. D4, D6, L1, L2

\section{ABSTRACT}

We develop a new model of quality to capture the idea that even if a customer chooses to purchase a product, it may fail to "deliver." In this event, the customer may wish to choose some other product. We model this as a two stage game where firms first choose quality and then price. We find that in equilibrium, the high quality firm (the one with a higher probability of being able to "deliver") will always make higher profits than the low quality one even if costs of quality are sharply increasing. Our work thus provides a reason for high quality niches to be inherently more profitable. The implications for welfare and equilibrium under free entry are also studied.

Kala Krishna

Department of Economics

The Pennsylvania State University

University Park, PA 16802

and NBER

kmk4@psuvm.psu.edu
Tor Winston

Department of Economics

The Pennsylvania State University

University Park, PA 16802 


\section{Introduction}

Quality is a fundamental source of heterogeneity among products. A casual observation of almost any market will reveal that firms compete on the basis of quality as much as on price and that often high prices are justified by claims of high quality. Early contributions to the large economic literature of quality models, decomposed products into the services they provided, see [17]. According to this "services" approach, a higher quality good merely embodied more services. Thus, a light bulb which lasted 200 hours was seen as being twice the quality of one which lasted only 100 hours. In these models firms minimize the cost per service and then choose the level of services which maximize profits.

Later work interprets quality more generally as anything that would induce consumers to pay more. A variety of applications have been developed to explore issues such as the effect of regulation on quality, see [15] and [11], price discrimination by a monopolist in the presence of information problems, see [6], and the choice of quality as a location issue, see [9]. [10] and others, have studied multi stage games where firms precommit to quality and then compete in price or output choices.

In all these models, consumers choose to buy one product or another. In contrast to this, in a number of settings it may be more appropriate to think of a customer purchasing a product knowing that it may fail to "deliver". If the product delivers, the consumer leaves the market with whatever payoff the product yields. If it does not deliver, the customer may wish to choose some other product. In this setup, a product is defined by the probability that it actually delivers as well as the payoff when it does deliver ${ }^{1}$.

Many situations have the flavor of this model. For example, an auto repair shop may not fix a particular defect effectively so that another may have to be visited. One doctor may be unable to cure a patient, where as another may succeed. Purchases of shoes which may not actually end up being the right fit is another!

This is the setting explored in this paper. We model a two stage game where firms first chose quality and then price. We show that in equilibrium, the high quality firm (the one with a higher probability of being able to "deliver") always makes higher profits than the firm with low quality even

\footnotetext{
${ }^{1}$ Due to the possibility of returning to the market, the value of choosing a product differs from the product of the payoff and the probability.
} 
if costs of establishing quality are sharply increasing. Our model provides a theoretical reason for why high quality niches may be more profitable, supporting the common business school idea that "the money is at the high end"2. This perception has been difficult for Economists to explain. Some tend to think that it is a result of not accounting for all relevant costs. In neoclassical models, investments in advertising, research and development or cultivation of a loyal customer base via early discounting, not high quality per $s \dot{e}$, are seen as reasons for current high profits. In fact, in standard models of vertical product differentiation such as [10], higher quality firms may make lower profits once all costs are accounted for.

Increasing quality is also seen as a means of reducing costs by reducing defects and material wastage as well as warranty claims and costs associated with recalls of products. A defective two cent resistor soldered into a computer component may cost a hundred dollars to repair [5]! According to [14], faulty checks account for half of all annual check processing costs in U.S. banks and Firestone's recall of radial tires cost $\$ 135$ million, more than the firms net income for that year.

There are also reputation effects to consider. These seem to be asymmetric, in that reputation is easier to lose than to gain! A leading manufacturer of appliances estimated that while satisfied consumers conveyed their experiences to three other people, dissatisfied ones talked to fifteen. A big three auto maker found that one dissatisfied owner of a luxury car cost the company no fewer than 100 sales in a single year ${ }^{3}$ ! A study by Ford [3] showed that satisfied customers tell eight other people about their car while dissatisfied ones tell 22 !

However, none of this can provide a reason why higher quality is more profitable. If faults are expensive, then profit maximizers will reduce faults until the marginal costs of reducing faults equals the benefit. Then firms which choose above the optimum quality levels make lower, not higher, profits than optimizing firms!

\footnotetext{
${ }^{2}$ In contrast to this, Porter, see [8], takes the view supported by standard models of product differentiation. He argues that quality as such does not raise profits. Rather, he focuses on the role of product differentiation in reducing the extent of price competiton. He highlights the importance of finding a "niche" so as to differentiate your product from the competition. He argues that product differentiation on the basis of quality creates a defensible competitive position and insulates a firm from competitve pressures in a way that competing solely on the basis of price and low costs could not achieve.

${ }^{3}$ See $[16]$ for more on this.
} 
There are a number of case studies that suggest that better product quality raises profitability, see [12],[13]. Peters and Waterman, [7], study well managed U.S. companies and argue that those that are most profitable also emphasize product and service quality. Changes in market share and changes in product quality are shown to be strongly related in [2], while advertising had only a modest relationship with market share, and price changes had no relationship with market share!

Table 1 reproduces a table from [1]. It uses 1970's data from the Profit Impact of Marketing Strategies (PIMS) study which involved 1,200 businesses. It shows that both the return on investment and profits as a percentage of sales revenue rise with quality. The more recent data in Table 2, reproduced from a table in [4], shows that the return on investment rises with quality, independent of how a firm's costs compare to its competitors'.

Our model suggests a reason for the association between higher quality and higher profits. Consumers who buy a good and are not satisfied re-enter the market and have to buy again. Higher quality goods have a higher probability of satisfying the consumer than lower quality ones. This is why firms who make higher quality products can charge enough to cover the additional costs of higher quality. Moreover, unequal quality choices constitute a Nash equilibrium even though firms are ex ante symmetric. Our model also suggests that in equilibrium, "sales" of lower quality goods are more likely than of higher quality goods.

In Section 2 we look at a simple duopoly model where the payoff to the consumer when the product delivers is the same across the two firms, but the probability of delivery, $q$, differs between firms. We assume that there are a continuum of identical consumers who obtain the benefit $V$ from the product when it does deliver, and zero when it fails to satisfy. We assume that marginal costs of production are zero. We show that a pure strategy equilibrium does not exist and construct the mixed strategy equilibrium.

In Section 3 we look at firms' quality choices. Section 4 provides a welfare analysis and compares the equilibrium to the welfare optimum. In Section 5 we allow for non zero marginal costs of production. Section 6 contains some concluding remarks. 


\section{The Model}

There are two stages to the game. In the first stage, firms choose the probability with which their product will satisfy the customer. This probability is interpreted as the quality of the product and represented by $q_{i}, i=1,2$. The fixed and sunk costs of producing a product of a given quality are incurred at this stage and are given by $C\left(q_{i}\right)$. In the second stage, the two firms compete in price and sell to a continuum of identical consumers with unit mass ${ }^{4}$. For given prices a consumer chooses which firm to buy from first. If that firm satisfies him, he goes no further. If it does not, he chooses whether to try the second firm or to quit ${ }^{5}$. All participants are assumed to be risk neutral.

As is standard we begin by solving the consumer's problem. We then use these results to solve for equilibrium in the second stage, which in turn forms the basis for solving for the equilibrium in the first stage.

\subsection{The Consumer's Problem}

The consumer's problem is particularly simple. Each of the identical consumers must choose which firm to buy from first and whether or not to visit the other firm if the first does not deliver. The consumer chooses to visit a firm as long as it expects a positive payoff, that is as long as $q_{i} V-P_{i}$ is positive. Assuming that both firms are patronized, he chooses to visit the firm with the lower value of $\frac{P}{q}$ first. $^{6}$

\subsection{Competition in Prices}

In the second stage firms take their quality choices as given and essentially compete in prices. It turns out to be convenient to depict a firm's profit and choices in terms of its price quality ratio, rather than of prices alone, as this ratio determines the consumers' switching behavior.

\footnotetext{
${ }^{4}$ Firms have zero marginal costs of production. Dropping the assumption that marginal costs are zero does not affect the flavor of the results as shown below.

${ }^{5}$ Once a firm is visited, it is removed from the set of possible choices.

${ }^{6}$ This is a simple application of the "Buried Treasure Problem". A treasure worth $V$ could be buried in any of $N$ locations. Digging at location $i$ costs $P_{i}$ and the probability of finding the treasure in location $i$ is $q_{i}$. The solution to this problem involves choosing to dig where $\frac{q_{i} V-P_{i}}{q_{i}}$ is highest, that is, where $\frac{P_{i}}{q_{i}}$ is lowest and all sites where $q_{i} V-P_{i}$ is positive are visited. Generalizations of such problems are dealt with in ([18]).
} 
First, consider the case where $\frac{P_{L}}{q_{L}}<\frac{P_{H}}{q_{H}}$. In this event the consumer visits firm $L$ first and pays $P_{L}$. With probability $1-q_{L}$ the consumer is not satisfied and subsequently visits firm $H$. Since there are a continuum of identical consumers, a fraction $1-q_{L}$ of them visit firm $H$ as well as $L$. If, on the other hand $\frac{P_{L}}{q_{L}}>\frac{P_{H}}{q_{H}}$, then the consumer visits firm $H$ first and pays $P_{H}$. With probability $1-q_{H}$ the consumer is not satisfied and subsequently visits firm $L$. Therefore a fraction $1-q_{H}$ of them visit firm $L$ as well as $H^{7}$.

Hence, the profits of firm $H$ are given by:

$$
\begin{array}{c|c}
\pi_{H}\left(P_{L}, P_{H} \mid q_{H}, q_{L}\right)=P_{H} \quad \text { if } \frac{P_{H}}{q_{H}}<\frac{P_{L}}{q_{L}} \\
=P_{H}\left(1-q_{L}\right) \text { if } \frac{P_{H}}{q_{H}}>\frac{P_{L}}{q_{L}} .
\end{array}
$$

The heavy line in Figure 1 depicts Firm $H^{\prime} s$ profits as a function of its price quality ratio. For price quality ratios below $\frac{P_{L}}{q_{L}}$, it has a slope of $q_{H}^{8}$ while above $\frac{P_{L}}{q_{L}}$, the slope is $\left(1-q_{L}\right) q_{H}$. Firm $L$ 's profits can be analogously defined and are depicted in Figure 2.

Notice that profits jump down at the point where $\frac{P_{H}}{q_{H}}=\frac{P_{I}}{q_{L}}$ and are increasing in the firm's price quality ratio above this point. Hence, if a firm chooses to price above this switchover point, it will choose a price quality ratio of $V$,the highest possible ratio which will still attract customers.

Let $\frac{P_{H}^{2}}{q_{H}}$ denote the level of $\frac{P_{H}}{q_{H}}$ such that the profits earned at $\frac{P_{H}^{*}}{q_{H}}$ when Firm $H$ is visited first are equal to its profits when it chooses $V$ and is visited second. This is shown in Figure 1.The horizontal line set at the height of $q_{H}\left(1-q_{L}\right) V$ (which is the level of profits obtained by the high quality firm by pricing at $V$ ) intersects the profits obtained assuming that Firm $H$ has the lower price quality ratio at $\frac{P_{H}^{*}}{q_{H}}$. In other words, $P_{H}^{*}=\left(1-q_{L}\right) q_{H} V$. Hence

$$
\frac{P_{H}^{*}}{q_{H}}=\left(1-q_{L}\right) V
$$

\footnotetext{
${ }^{7}$ Note that we specify that the price is paid up front and not refunded if the product fails to deliver. If we assume that firms can "guarantee satisfaction or your money back" the problem becomes the usual Bertrand one as consumers choose the firm with the lowest price.

${ }^{8}$ This is because profits are drawn as a function of $\frac{P_{\mu H}}{q_{H}}$ so that firm $H^{\prime} s$ profits are given by $\left(\frac{P_{H}}{q_{H}}\right) q_{H}$ and the slope of the profit function is $q_{H}$.
} 
and $\frac{P_{L}^{*}}{q_{L}}$ is analogously defined as

$$
\frac{P_{L}^{*}}{q_{L}}=\left(1-q_{H}\right) V
$$

At this stage it is useful to impose a tie-breaking rule.

Assumption The lowest quality firm not previously visited is visited first in the event of a tie. In the two firm case, if both firms choose the same price-quality ratio the consumer visits Firm $L$ first.

Now note that if $\frac{P_{L}}{q_{L}} \leq \frac{P_{H}^{*}}{q_{H}}$, then $H^{\prime}$ 's best response is to choose a price quality ratio of $V$. If $\frac{P_{L}}{q_{L}}>\frac{P_{H}^{*}}{q_{H}}$ then $H$ 's best response is to choose a price quality ratio just a little below $\frac{P_{L}}{q_{L}}$. Firm $L$ 's best response function is analogously characterized. These best responses are depicted in Figure 3. It is clear from Figure 3 that the best response functions do not intersect so that there are no pure strategy equilibria in this game.

If $L$ chooses a price-quality ratio weakly below $\frac{P_{H}^{*}}{q_{H}}, H$ 's best response is to choose his monopoly price-quality ratio, $V$ and only serve those customers who were not satisfied when they visited firm $L$. If $H$ prices in this way, then it is best for $L$ to just undercut him so that this cannot be an equilibrium. If,$L$ chooses a price-quality ratio above $\frac{P_{H}^{*}}{q_{H}}, H$ 's best response is to just undercut him and get all consumers to visit him first. But if $H$ prices in this way, then it is best for $L$ to just undercut him so that this cannot be an equilibrium.

Proposition 1 There are no pure strategy equilibria when two firms campete in prices for given qualities.

Given Proposition 1 we turn our attention to the existence of mixed strategy equilibria ${ }^{9}$. We begin by restricting the support of the mixed strategy

\footnotetext{
${ }^{9}$ One might suspect that a simple mixed strategy equilibrium exists, namely one where $H$ randomizes between $\frac{P_{H}^{*}}{q_{H}}$ and $V$ while $L$ plays $\frac{P_{H}^{*}}{q_{H}}$. However, this is not an equilibrium. If $L$ is assumed to be visited first (or if firms are visited randomly) in the event of a tie, then $H$ prefers $V$ to $\frac{P_{H}^{i}}{q_{H}}$ so that this is not an equilibrium. If $H$ is visited first in the event of a tie then $L$ prefers to charge slightly less than $\frac{P_{H}^{*}}{q_{H}}$ ensuring he is visited first so that this is not an equilibrium either.
} 
equilibria. First, note that any price quality ratio below $\frac{P_{i}^{*}}{q_{i}}$ yields lower profits, no matter what the other firm chooses to do, than the price quality ratio of $V$. By charging a price quality ratio of $V$, thereby always being the higher priced firm, $L$ can ensure itself a payoff of at least $\left(1-q_{H}\right) q_{L} V$. Similarly, firm $H$ can ensure itself the payoff of $\left(1-q_{L}\right) q_{H} V$. Thus, price-quality ratios below $\frac{P_{i}^{*}}{q_{i}}$ for firm $i$ are strictly dominated and will never be used in equilibrium.

Second, note that choosing any price quality ratio greater than $V$ is also dominated by choosing $V$ since charging a price-quality ratio exceeding $V$ ensures that no customers will buy the product.

Third, note that the lower bounds of the supports of the two firm's mixed strategies must be the same. If these lower bounds were not equal, then the expected profits of the firm with the lower bound evaluated at its lower bound, would be increasing in its price-quality ratio, as at this price it is the customers first choice with certainty. Hence this could not be part of a mixed strategy equilibrium ${ }^{10}$.

From (1) and (2) it follows that $\frac{P_{H}^{*}}{q_{H}}>\frac{P_{i}^{*}}{q_{L}}$, so that neither firm will choose a price-quality ratio below $\frac{P_{H}^{*}}{q_{H}}$ in equilibrium. These results show that the following Lemma holds.

Lemma 2 The support of the mixed strategies of the two firms must lie in the interval $\left[\frac{P_{H}^{P}}{q_{H}}, V\right]$.

In Appendix 1 we show that this interval in fact constitutes the support of the both mixed strategies in equilibrium and characterize the mixed strategy equilibrium itself.

\footnotetext{
${ }^{10}$ Recall also that a firm must be indifferent over all points it mixes over. Thus if $\frac{P_{H}^{*}}{q_{H}}$ and $V$ lie in the support of prices charged by firm $H$ in the mixed strategy equilibrium, their expected profits at these two points must be equal. We will use this fact extensively below.
} 
Proposition 3 In equilibrium the two firms will choose the following unique mixed strategies.

$$
\begin{array}{rlrl}
F_{L}\left(\frac{P}{q}\right) & =\frac{1}{q_{L}}-\frac{\left(1-q_{L}\right) V}{q_{L}}\left(\frac{P}{q}\right)^{-1} \text { for } \frac{P}{q} \in\left[\left(1-q_{L}\right) V, V\right] \\
F_{H}\left(\frac{P}{q}\right) & =\frac{1}{q_{H}}-\frac{\left(1-q_{L}\right) V}{q_{H}}\left(\frac{P}{q}\right)^{-1} & \text { for } \frac{P}{q} \in\left[\left(1-q_{L}\right) V, V\right) \\
& =1 \quad \text { for } \frac{P}{q}=V .
\end{array}
$$

Note that $F_{H}(V)=\frac{q_{L}}{q_{H}}<1$, which implies that the high quality firm has a mass point of $\left(1-\frac{q_{L}}{q_{H}}\right)$ at the price-quality ratio $V^{11}$. A proof of Proposition 3 is given in Appendix 1. It is easy to verify that this set of strategies in fact constitutes an equilibrium. Given that $L$ is randomizing over prices as defined above, the expected profit for Firm $H$ of a price quality ratio in the interval $\left[\left(1-q_{L}\right) V, V\right)$ is given by:

$$
\begin{aligned}
E\left(\pi_{H}\left(P_{H}\right)\right) & =F_{L}\left(\frac{P_{H}}{q_{H}}\right)\left(1-q_{L}\right) P_{H}+\left(1-F_{L}\left[\frac{P_{H}}{q_{H}}\right]\right) P_{H} \\
& =P_{H}-F_{L}\left[\frac{P_{H}}{q_{H}}\right] q_{L} P_{H} \\
& =P_{H}-\left[\frac{1}{q_{L}}-\frac{\left(1-q_{L}\right) V}{q_{L}}\left(\frac{P_{H}}{q_{H}}\right)^{-1}\right] q_{L} P_{H} \\
& =\left(1-q_{L}\right) q_{H} V
\end{aligned}
$$

which is independent of $P_{H}$.

For this to be an equilibrium, $\frac{P_{H}}{q_{H}}=V$ must yield the same expected profits. In this case, Firm $H$ gets profits of $\left(1-q_{L}\right) q_{H} V$ with probability $\frac{q_{L}}{q_{H}}$ and $q_{L} V$ with probability $\left(1-\frac{q_{L}}{q_{H}}\right)$, so that expected profit are the same as

${ }^{11}$ Looking at Figure 2 shows that the profits of $L$ when it chooses the price-quality $V$, and is visited second, are less that its profits at the price ratio $=\left(1-q_{L}\right) V$. To equalize them so that they can both be in the support of the distribution, firm $H$ needs to have a mass point at $V$. This mass point, in conjunction with the assumption that Firm $L$ is visited frst in the event of a tie, ensures that when Firm $L$ charges $V$ it is visited first with finite probability and can obtain profits equal to those at $\frac{P_{H}^{*}}{q_{H}}$. 
those obtained in the range $\left[\left(1-q_{L}\right) V, V\right)$. For price-quality ratios below $\left(1-q_{L}\right) V$, expected profits are $P_{H}$. These cannot exceed their value at $\frac{P_{H}}{q_{H}}$ $=\left(1-q_{L}\right) V$. Hence Firm $H$ will not choose any price quality ratio below $\left(1-q_{L}\right) V$.

Similarly, the expected profits of $L$ for price-quality ratios in the interval $\left[\left(1-q_{L}\right) V, V\right)$ are given by:

$$
\begin{aligned}
E\left(\pi_{L}\left(P_{L}\right)\right) & =F_{H}\left(\frac{P_{L}}{q_{L}}\right)\left(1-q_{H}\right) P_{L}+\left(1-F_{H}\left[\frac{P_{L}}{q_{L}}\right]\right) P_{L} \\
& =P_{L}-F_{H}\left[\frac{P_{L}}{q_{L}}\right] q_{H} P_{L} \\
& =P_{L}-\left[\frac{1}{q_{H}}-\frac{\left(1-q_{L}\right) V}{q_{H}}\left(\frac{P_{L}}{q_{L}}\right)^{-1}\right] q_{H} P_{L} \\
& =\left(1-q_{L}\right) q_{L} V
\end{aligned}
$$

which is independent of $P_{L}$.

If $\frac{P_{L}}{q_{L}}=V, L$ gets profits of $\left(1-q_{H}\right) P_{L}=\left(1-q_{H}\right) q_{L} V$ which are the same as those obtained in $\left(\left(1-q_{L}\right) V, V\right)$. For price-quality ratios below $\left(1-q_{L}\right) V$, expected profits are $P_{L}$ which cannot exceed $\left(1-q_{L}\right) q_{L} V$. Hence $L$ will not choose any price quality ratio below $\left(1-q_{L}\right) V$. Therefore, both $L$ and $H$ will be content to randomize as indicated ${ }^{12}$. Notice that the total profits of the firm with the lower quality are independent of the quality chosen by the higher quality firm, as long as their quality ranking is unchanged. Now we turn to the issue of how quality is chosen.

\section{Choosing Quality}

Firms realize that their choice of quality will affect their profits in the subsequent stage and they incorporate this information into their decision making

\footnotetext{
${ }^{12}$ It is worth pointing out that in this model, expected profits in the mixed strategy equilibrium are identical with the profits obtained by charging the lowest price in the common support. This in turn is easy to calculate as it equals the profits from being the first firm visited at that price.
} 
in the first stage. The profit function for firm $i$, given that its rival chooses the quality $q_{-i}$, is a composite function denoted by $\Pi_{i}\left(q_{i}, q_{-i}\right)$ where:

$$
\begin{aligned}
\Pi_{i}\left(q_{i}, q_{-i}\right) & =\left(1-q_{i}\right) q_{i} V-C\left(q_{i}\right) \text { for } q_{i} \leq q_{-i} \\
& =\left(1-q_{-i}\right) q_{i} V-C\left(q_{i}\right) \text { for } q_{i} \geq q_{-i} .
\end{aligned}
$$

Note that the firm's profit function is continuous in $q_{i}$ for any $q_{-i}$ chosen by its competitor. Firms choose their quality to maximize their total profits, given the quality chosen by their competitor. This results in the best responses in quality space, which we define below. We look at two timing structures. First we look at the case where firms choose their qualities simultaneously. Then we turn to the case where they choose them sequentially.

\subsection{Simultaneous Choices}

It turns out to be useful to break the problem up into two parts. First we consider the case where $C\left(q_{i}\right)$ is concave and increasing in $q_{i}$. Then we turn to the case where $C\left(q_{i}\right)$ is convex and increasing in $q$. The notation used in this discussion is summarized in Table 3.

\subsubsection{Concave Costs}

Figure 4 illustrates the shape of profits for firm $i$ as a function of its quality, given $q_{-i}$. Its profits correspond to those for the low quality firm for $q$ below $q_{-i}$ and to those for the high quality firm for $q$ above $q_{-i}$. Start with $q_{-i}=q$ for concreteness. The switchover between the two components of its profits occurs at $q_{-L}$ as depicted in Figure 4. However, as profits are continuous in quality there is no jump at this switchover point. As $q_{-i}$ rises, to $q^{\prime}$ and further to $\tilde{q}_{L},\left(1-q_{-i}\right) q_{i} V-C\left(q_{i}\right)$ falls, shifting the latter component of the composite function down as shown in Figure 4 . The composite profit function for $q_{-i}=q^{\prime}>q$ is given by the bold line in Figure 4 .

Let $q$ denote the level of $q$ that maximizes $(1-q) q V-C(q)$. Thus, ${ }_{-L}$ is defined by the first order condition:

$$
(1-2 \underset{-}{q}) V-C^{\prime}\left(\underline{q}_{L}\right)=0 .
$$

Thus, $\Pi_{L}\left(\underline{q}_{L}\right)=\underline{\Pi}_{L}$ is the maximum profit $L$ can attain. We assume this 
is positive. Note that as $(1-q) q V$ attains its maximum at $q=1 / 2$, the maximum of $(1-q) q V-C(q)$ must occur at $q<1 / 2$.

Next, consider the components of $\Pi_{H}(q) \cdot\left(1-q_{-i}\right) q V$ is linear in $q$ and decreasing in $q_{-i}$. If $-C\left(q_{i}\right)$ is convex in $q$, as it is when $C($.$) is concave,$ $\Pi_{H}(q)$ must be convex in $q$ so that the profits of the high quality firm are maximized at the corner solution, $q=1$. Let the profits associated with this choice, given that the other firm chooses $q_{L}$, be denoted by $\Pi_{H}\left(1, q_{L}\right)$. Similarly, if firm $L$ chooses $\frac{q}{-}$, Firm $H$ can obtain profits of $\Pi_{H}\left(1, \underline{q}_{L}\right)$.

Note that the slope of $\Pi_{H}^{-L}\left(q, q_{L}\right)$ evaluated at $q={ }_{-L}$ is given by:

$$
\left(1-\underline{q}_{L}\right) V-C^{\prime}\left(\underline{q}_{L}\right) \text {. }
$$

Comparing the slopes of $\Pi_{H}\left(q, \underline{q}_{L}\right)$ and $\Pi_{L}(q)$ at $q={ }_{-L}$, that is comparing (7) with (6), reveals that the slope of the former exceeds that of the latter (which equals zero) as depicted in Figure 4 . This is why the high quality firm makes greater profits in equilibrium than the low quality one.

Let $\tilde{q}_{L}$ be defined by

$$
\Pi_{H}\left(1, \tilde{q}_{L}\right)=\Pi_{L}\left(\underline{q}_{L}\right) .
$$

and recall that $\underline{-}_{L}$ was defined by (6). Thus,

Lemma $41>\bar{q}_{L}>\frac{q}{-L}$.

Recall that $\Pi_{H}\left(q, q_{L}\right)=\Pi_{L}\left(\underline{q}_{L}\right)$ at $q_{L}=q$. As $\Pi_{H}\left(q, q_{L}\right)$ is increasing in $q, \Pi_{H}\left(1, \underline{q}_{L}\right)>\Pi_{L}\left(\underline{q}_{L}\right)$. Since $\Pi_{H}\left(q_{H}, q_{L}\right)$ is decreasing in $q_{L}, q_{L}$ must rise from $\underline{q}_{L}$ to $\tilde{q}_{L}$ for $\Pi_{H}\left(1, \tilde{q}_{L}\right)=\Pi_{L}\left(\underline{q}_{L}\right)$. Hence $\tilde{q}_{L}>\underline{q}_{L}$. This is depicted in Figure 4. The value of $\Pi_{H}\left(q, q_{L}\right)$ at $q_{L}=1$ is negative. As, $\Pi_{L}\left(\underline{q}_{L}\right)$ is positive it follows by continuity arguments that $\tilde{q}_{L}<1$.

The form of the best response functions is now clear. A firm chooses a quality of $q$ if its opponent chooses a quality $q_{-i} \geq \tilde{q}_{L}$, and chooses a quality of 1 for $q_{-i} \leq \tilde{q}_{L}$. Thus there are two equilibria at points $A$ and $B$ as depicted in Figure 5. They are mirror images of one another where one firm chooses $q_{L}$ and the other chooses $q=1$. Our results so far are summarized below. 
Proposition 5 When costs of quality are concave and non decreasing in $q$ there are two pure strategy equilibria, which are mirror images of one another, where one firm chooses $q$ and the other chooses $q=1$. In equilibrium, the high quality firm makes greater profits than the low quality firm.

We now turn to the case with convex costs of quality.

\subsubsection{Convex Costs}

As $C\left(q_{i}\right)$ is convex, the latter segment of the total profit function (corresponding to being the high quality firm) is concave. This is depicted in Figure 6 which is analogous to Figure 4. As a consequence, if the firm chooses to operate on this latter segment, it need not be best off choosing a quality of 1 . Let $q_{H}\left(q_{L}\right)$ denote the profit maximizing choice of quality in this case $\mathrm{e}^{13}$. This best response is implicitly defined by:

$$
\left(1-q_{L}\right) V-C^{\prime}\left(q_{H}\left(q_{L}\right)\right)=0
$$

provided that $\left(1-q_{L}\right) V-C^{\prime}(1)<0$. Of course, if a corner solution occurs and $\left(1-q_{L}\right) V-C^{\prime}(1) \geq 0$, then $q_{H}\left(q_{L}\right)=1$. Note that $q_{H}\left(q_{L}\right)$ is weakly downward sloping. Let the maximized profits along $q_{H}\left(q_{L}\right)$ be denoted by $\Pi_{H}\left(q_{H}\left(q_{L}\right)\right.$, $q_{L}$ ). Likewise, let the profits associated with choosing this quality, assuming that $L$ chooses $q$ be denoted by $\Pi_{H}\left(q_{H}\left(\underline{q}_{L}\right), \underline{q}_{L}\right)$. As in the concave cost case, the slope of $\Pi_{H}(q, q)$, evaluated at $q=-_{-L}^{q}$, exceeds that of $\Pi_{L}(q)$ which is
zero.

In this case it is easy to see that there is a pure strategy equilibrium. The best response function of a firm will be either $q_{H}\left(q_{L}\right)$ or $\frac{q}{L}$, depending on which gives greater profits. We show that it is $q_{H}\left(q_{L}\right)$ if the other firms quality choice is low enough and is $\frac{q}{-}$ if the other firm chooses a quality above a critical level denoted by $\hat{q}_{L} . \hat{\hat{q}}_{L}^{L}$ is defined by

$$
\Pi_{H}\left(q_{H}\left(\hat{q}_{L}\right), \hat{q}_{L}\right)=\Pi_{L}\left(\underline{q}_{L}\right) \text {. }
$$

Let $q_{L}^{c}$ denote the value of $q_{L}$ where $q_{H}\left(q_{L}\right)$ intersects the 45 degree line. That is:

$$
q_{H}\left(q_{L}^{c}\right)=q_{L}^{c} .
$$

\footnotetext{
${ }^{13}$ We assume that as $q$ goes to zero, the slope of $C($.$) also goes to zero. This ensures$ that a quality choice of zero is not optimal.
} 
Lemma $6 \underset{-L}{q}<\hat{q}_{L}<q_{L}^{c}$ where $\hat{q}_{L}$ and $q_{L}^{c}$ are defined in (10) and (11) respectively,

Again recall that $\Pi_{H}\left(q, \underline{q}_{L}\right)$ is concave and increasing in $q$ as well as being equal to $\Pi_{L}\left(\underline{q}_{L}\right)$ when $q=\underline{q}_{L}$. Thus, $\Pi_{H}\left(q_{H}\left(\underline{q}_{L}\right), \underline{q}_{L}\right)>\Pi_{L}\left(\underline{q}_{L}\right)$ and $q_{H}\left(\underline{q}_{L}\right)>\underline{-q}_{L}$. From this and as $\Pi_{H}\left(q_{H}\left(q_{L}\right), q_{L}\right)$ decreases in $q_{L}$ it follows that $\hat{q}_{L}>\underline{q}_{L}$.

$q_{L}^{c}$ is uniquely defined and greater than $q_{-L}$ as $q_{H}\left(q_{L}\right)$ is downward sloping and lies above the 45 degree line at $q_{L}=q{ }_{-L}$.

From the definition of $\Pi_{H}\left(q_{H}\left(q_{L}\right), q_{L}\right)$ and the fact that the switchover in profits occurs along the 45 degree line, its value at $q_{L}=q_{L}^{c}$ is given by:

$$
\begin{aligned}
\Pi_{H}\left(q_{H}\left(q_{L}^{c}\right), q_{L}^{c}\right) & =\Pi_{H}\left(q_{L}^{c}, q_{L}^{c}\right) \\
& =\Pi_{L}\left(q_{L}^{c}\right) \\
& <\Pi_{L}\left(q_{L}\right) \\
& =\Pi_{H}\left(q_{H}\left(\hat{q}_{L}\right), \hat{q}_{L}\right) .
\end{aligned}
$$

Since $\Pi_{H}\left(q_{H}\left(q_{L}\right), q_{L}\right)$ falls as $q_{L}$ rises, it follows that $\hat{q}_{L}<q_{L}^{c}$ which completes the proof.

The form of the best response functions and the equilibrium is now clear. A firm chooses a quality of $q$ if its opponent chooses a quality $q_{-i} \geq \hat{q}_{L}$ and chooses a quality of $q_{H}\left(q_{L}\right)$ if $q_{-i} \leq \hat{q}_{L}$. The best responses look much like those in the case of concave costs. The only difference is that in the concave cost case they could be downward sloping for low $q$ choices by the opponent.

The best response functions are drawn in Figure 7. Two pure strategies can be seen to exist as a consequence of the fact that $q<\hat{q}_{L}<q_{L}^{c}$. These are mirror images of one another, at points $A$ and $B$. In equilibrium, one firm chooses $q_{-}$and the other chooses $q_{H}\left(\underline{q}_{L}\right)$. Note that once again the high quality firm must always make greater profits in equilibrium than the low quality one. Our results so far are summarized below.

Proposition 7 When costs of quality are convex in $q$ there are two pure strategy equilibria. These are mirror images of one another, where one firm chooses $q_{L}$ and the other chooses $q_{H}\left(\underline{q}_{L}\right)$. In equilibrium, the high quality firm makes greater profits than the low quality one. 


\subsection{Sequential Choices}

Here again it is worth considering the concave costs of quality separately from the convex case. In the concave case the first mover has to essentially choose between the two equilibria $A$ and $B$ in Figure 5. Of course, he chooses to be the high quality producer. Hence, the Stackelberg equilibrium is a subset of the Nash equilibria.

With convex costs of quality, the first mover (whose quality is on the vertical axis) can choose $A$ to be the equilibrium as the best response function of the opponent is flat if the first mover chooses $A$ as depicted in Figure 7. As profits are higher at $A$ for the firm labelled $H$ than at the points $K$ and $L$ (where profits are equal) they exceed profits along the downward sloping part of the opponents best response function. Hence, the Stackelberg point for the first firm to enter remains at $A$.

Proposition 8 The firm which moves first will produce a higher quality and earn higher profits whether costs of quality are concave or convex.

\section{Welfare}

In this section we ask whether the quality chosen by firms is socially optimal or not. Recall that as demand is completely inelastic, there is no distortion caused by the existence of market power, for given quality levels. If prices are high, firms get a greater share of the social surplus than if prices are low, but the sum of consumer and producer surplus is constant. However, the level of the social surplus itself could be sub-optimal if the quality choices of the firms differ from those a social planner would make.

As usual, social welfare equals the sum of consumer and producer surplus as we assume there is a numeraire good and all profits are returned to consumers in a lump sum. Since price paid enters negatively into consumer surplus, but positively into producer surplus, it cancels out in the social welfare calculations. Social welfare is denoted by $W$ and is given below. The price quality ratio $\frac{P_{H}}{q_{H}}$ occurs with probability $F_{H}^{\prime}\left(\frac{P_{H}}{q_{H}}\right)$. If firm $L$ chooses a lower price quality ratio than that of firm $H$, it is visited before firm $H$ and $V$ is obtained with probability $q_{L}+\left(1-q_{L}\right) q_{H}$. If firm $L$ chooses a higher price quality ratio than that of firm $H$, it is visited after firm $H$ and $V$ is obtained with probability $q_{H}+\left(1-q_{H}\right) q_{L}$. Integrating over all the prices charged by firm $H$ and subtracting production costs gives the expression below. 


$$
\begin{aligned}
W= & \int_{\left(1-q_{L}\right) V}^{V} F_{H}^{\prime}\left(\frac{P_{H}}{q_{H}}\right)\left\{F_{L}\left(\frac{P_{H}}{q_{H}}\right)\left[q_{L} V+\left(1-q_{L}\right) q_{H} V\right]\right. \\
& \left.+\left[1-F_{L}\left(\frac{P_{H}}{q_{H}}\right)\right]\left[q_{H} V+\left(1-q_{H}\right) q_{L} V\right]\right\} d\left(\frac{P_{H}}{q_{H}}\right) \\
& -C\left(q_{L}\right)-C\left(q_{H}\right)
\end{aligned}
$$

Collecting terms and simplifying results in:

$$
W=V\left[q_{H}+\left(1-q_{H}\right) q_{L}\right]-C\left(q_{L}\right)-C\left(q_{H}\right) .
$$

This is a particularly simple symmetric form. $q_{H}$ and $q_{L}$ can be interpreted as the quality levels of the two firms. As demand is completely inelastic, there is no monopoly distortion and no dead weight loss of pricing above marginal costs. However, if quality is not perfect, $q_{i} \neq 1$, then the utility of $V$ is not obtained by visiting firm $i$, but instead $V q_{i}$ is obtained. If the first try fails, a second chance to get $V$ can be obtained by visiting the other firm and this gives utility $V\left(1-q_{i}\right) q_{-i}$. Of course, the cost of having each firm is $C(q)$ so that it may be best to settle for only one try. If costs of quality are convex, it is expensive to have quality high so that it is best to opt for two chances at $V$ and choose equal levels of $q$ (due to the symmetry of the two firms) and a non zero probability of not getting $V$. If costs of quality are concave, it is not expensive to have quality very high so that it is best to be sure to get $V$ on the first try. This is what we show more formally below.

It is useful to look at the pseudo best responses of the social planner. These are defined as the choice of $q_{H}$ (or alternatively, $q_{L}$ ) which maximize social welfare for a given level of $q_{L}$ (or alternatively $q_{H}$ ). This is preferable to relying on first order conditions alone since welfare is not concave in its arguments when costs of quality are concave.

Consider the case with concave costs of quality. Welfare can be written as

$$
W=V\left\{q_{H}\left(1-q_{L}\right)+q_{L}\right\}-C\left(q_{L}\right)-C\left(q_{H}\right) .
$$

For a given $q_{L}$, the object is to maximize $V q_{H}\left(1-q_{L}\right)-C\left(q_{H}\right)$. This is maximized at $q_{H}=1$ if $\left(1-q_{L}\right)-C(1) \geq 0$ and at $q_{H}=0$ if $\left(1-q_{L}\right)-C(1) \leq 0$. Hence $q_{H}=1$ for $q_{L}$ close to zero and $q_{H}=0$ for $q_{L}$ close to unity with a 
switch at $q_{L}=1-C(1)$. Thus, the intersection of the pseudo best responses occurs at the points $(0,1)$ and $(1,0)$. It is optimal to have only one firm in the market producing a quality of unity. This makes sense as this policy gives a utility of $V$ at minimum cost.

Consider the case with convex costs of quality. Here as costs of quality rise sharply, it is optimal to allow a second firm so that consumers get a second chance to get $V$. In this way total utility, while short of $V$, is as high as possible. More formally, consider the pseudo best responses. As welfare is concave in its arguments these pseudo best responses are defined by the first order conditions:

$$
\frac{\partial W}{\partial q_{i}}=\left(1-q_{-i}\right) V-C^{\prime}\left(q_{i}\right)=0
$$

It is easy to see that this looks like the first order condition for firm $H$ which defined $q_{H}\left(q_{L}\right)$ earlier. Note that the socially optimal policy is to equalize the quality levels of the two firms. Comparing this with the Nash equilibrium and Stackelberg equilibrium gives the following.

Proposition 9 If costs of quality are concave, then it is optimal to have only one firm producing a quality of unity. In equilibrium, the quality chosen by the high quality firm is optimal, while that chosen by the low quality firm is higher than the socially optimal level of zero. If costs of quality are convex the quality chosen by the high quality firm is higher than the socially optimal level, while that chosen by the low quality firm is lower than what is socially optimal.

It is also worth comparing the choices of a monopolist with those of a planner. A monopolist will always charge a price of $V q$ as this is the common reservation price. Hence he will choose $q$ to maximize $V q-C(q)$. With concave costs of quality a monopolist sets $q=1$, the socially optimal level, assuming that it is optimal to produce at all. If costs of quality are convex, a quality level of $q_{m}$, which satisfies $V=C^{\prime}\left(q_{m}\right)$, is chosen by the monopolist. Comparing this with the conditions for optimality and duopoly shows the following.

Proposition 10 With concave costs of quality a monopolist chooses the socially optimal level of quality. If costs of quality are convex, he chooses a quality level which exceeds that chosen by the high quality firm in the duopoly, as well as the socially optimal level. If the monopolist is allowed to control more than one firm, then the socially optimal quality is chosen. 
This should not be surprising. As mentioned earlier, there is no monopoly distortion in this model. Having a monopoly distortion would tend to reduce the quality choice of the monopolist as he will produce less than the optimal output so that there will be fewer units to spread the costs of quality over.

\section{Allowing for Production Costs}

While we have assumed zero production costs for simplicity so far, our results are not dependent on this assumption. The model can easily be generalized to allow for non zero costs of production. Essentially, equilibrium has the same form as in the absence of production costs, with some small adjustments.

First consider the case where production costs are constant independent of quality. Let $c$ be these constant costs. Profits are now given by

$$
\begin{aligned}
\pi_{i}\left(P_{i}, P_{-i}\right) & =P_{i}-c \text { if } \frac{P_{i}}{q_{i}}<\frac{P_{-i}}{q_{-i}} \\
& =\left(P_{i}-c\right)\left(1-q_{-i}\right) \text { if } \frac{P_{i}}{q_{i}}>\frac{P_{-i}}{q_{-i}} .
\end{aligned}
$$

Again, we define $P_{i}^{*}$ such that expected profits from choosing $P_{i}^{*}$ are equal to the expected profit from choosing the maximum price. This yields,

$$
\frac{P_{i}^{*}}{q_{i}}=\left(1-q_{-i}\right)\left(V-\frac{c}{q_{i}}\right) \text {. }
$$

As earlier, $\frac{P_{H}^{*}}{q_{H}}>\frac{P_{i}^{*}}{q_{L}}$ and both firms mix over a common support $\left[\frac{P_{H}^{*}}{q_{H}}, V\right]$. We can solve for the mixed strategies to get $^{14}$ :

$$
\begin{aligned}
F_{L}\left(\frac{P}{q}\right) & =\frac{1}{q_{L}}-\frac{\left(1-q_{L}\right)\left(V-\frac{c}{q_{H}}\right)}{q_{L}}\left(\frac{P-c}{q}\right)^{-1} \text { for } \frac{P}{q} \in\left[\frac{P_{H}^{*}}{q_{H}}, V\right] \\
F_{H}\left(\frac{P}{q}\right) & =\frac{1}{q_{H}}-\frac{\left(1-q_{L}\right)\left(V-\frac{c}{q_{H}}\right)}{q_{H}}\left(\frac{P-c}{q}\right)^{-1} \text { for } \frac{P}{q} \in\left[\frac{P_{H}^{*}}{q_{H}}, V\right) \\
& =1 \quad \text { for } \frac{P}{q}=V
\end{aligned}
$$

\footnotetext{
${ }^{14}$ Essentially all that happens is that $V$ gets replaced by $\left(V-\frac{c}{q H}\right)$ while $\frac{P-c}{q}$ replaces $\frac{P}{q}$ in the previous formulae. In fact, it is easy to show that even marginal costs which are linear in quality produce the same kind of equilibrium. All that needs to be done to describe the equilibrium is to replace $c$ with $m q$ in the above where $m$ is a positive constant and $q$ is the quality of the product chosen.
} 
and

$$
\begin{aligned}
K_{H} & =\left(1-q_{L}\right) q_{H}\left(V-\frac{c}{q_{H}}\right) \\
K_{L} & =\left(1-q_{L}\right) q_{L}\left(V-\frac{c}{q_{H}}\right) .
\end{aligned}
$$

We now turn to the optimal choice of quality for each firm. The firms' profits are given by,

$$
\Pi_{H}\left(q_{H} ; q_{L}\right)=\left(1-q_{L}\right) q_{H}\left(V-\frac{c}{q_{H}}\right)-C\left(q_{H}\right)
$$

and

$$
\Pi_{L}\left(q_{L}\right)=\left(1-q_{L}\right) q_{L}\left(V-\frac{c}{q_{H}}\right)-C\left(q_{L}\right) .
$$

In this model, constant marginal costs of production which are independent of quality ensure that the choice of the low quality firm depends on that of the high quality firm. Nevertheless, as $q_{H}>q_{L}$, the firm with the higher quality in equilibrium makes greater profits.

We can also accommodate costs of production which rise with quality. Let the total cost of production be $m q_{i} X_{i}$ where $X_{i}$ is firm $i$ output. Thus, the marginal cost of production is constant and equal to $m q_{i}$.

$$
\begin{aligned}
\pi_{L}\left(P_{L}, P_{H}\right. & \left.\mid q_{H}, q_{L}\right)=P_{L}-m q_{L} \text { if } \frac{P_{H}}{q_{H}}>\frac{P_{L}}{q_{L}} \\
= & \left(P_{L}-m q_{L}\right)\left(1-q_{H}\right) \text { if } \frac{P_{H}}{q_{H}}<\frac{P_{L}}{q_{L}} . \\
\pi_{H}\left(P_{H}, P_{L}\right. & \left.\mid q_{H}, q_{L}\right)=P_{H}-m q_{H} \text { if } \frac{P_{H}}{q_{H}}<\frac{P_{L}}{q_{L}} \\
& =\left(P_{H}-m q_{H}\right)\left(1-q_{L}\right) \text { if } \frac{P_{H}}{q_{H}}>\frac{P_{L}}{q_{L}} .
\end{aligned}
$$

Again, we define $P_{i}^{*}$ such that expected profits from choosing $P_{i}^{*}$ are equal to the expected profit from choosing the maximum price. This yields

$$
\frac{P_{i}^{*}}{q_{i}}=\left(1-q_{-i}\right) V+m q_{-i} \text {. }
$$


We can solve for the mixed strategies to get

$$
F_{i}\left(\frac{P}{q}\right)=\frac{1}{q_{i}}-\frac{K_{-i}}{q_{i} q_{-i}\left(\frac{P}{q}-m\right)}
$$

Once again as, $q_{H}>q_{L}$ and $V>m, \frac{P_{i}^{i}}{q_{L}}<\frac{P_{H}^{*}}{q_{H}}$. Firm $H$ is then indifferent between pricing at $\frac{P_{H}^{M}}{Q_{H}}$ and pricing at $V$ and as before

$$
K_{H}=\left(1-q_{L}\right) q_{H}(V-m)
$$

and

$$
K_{L}=\left(1-q_{L}\right) q_{L}(V-m)
$$

We now turn to the optimal choice of quality for each firm and the effects of non-negative marginal cost on welfare. The firms' profits are given by

$$
\Pi_{H}\left(q_{H} ; q_{L}\right)=\left(1-q_{L}\right) q_{H}(V-m)-C\left(q_{H}\right)
$$

and

$$
\Pi_{L}\left(q_{L}\right)=\left(1-q_{L}\right) q_{L}(V-m)-C\left(q_{L}\right) .
$$

Applying the same profit maximization procedure used above we can analyze the effects on quality choices. The addition of marginal cost of production reduces the marginal benefit of quality. The resulting changes in the firms' choice of quality depend critically on the nature of the cost of quality function. With concave cost of quality, a high quality producer continues to choose perfect quality regardless of marginal cost of production as long as $\left(1-q_{L}\right)(V-m)>C(1)$. With convex cost of quality the both the low and high quality producers will reduce their optimal quality choices when accounting for nonzero marginal costs so that equilibrium quality choices fall.

\section{Conclusion}

In the model presented above, the probability of satisfying the customer plays a similar role to the number of services embodied in a unit of the product in the model of quality developed by Swan [17]. However, while quality was chosen to minimize the cost per unit of services by the producer (competitor 
or monopolist) in the Swan model of quality, it is chosen for strategic reasons in this model. Our equilibrium also requires mixed strategies in price. We interpret these as a policy of sales. In this context, our model suggests that lower quality products come on sale more often than higher quality ones, although they have a common support over which they randomize. There is a pure strategy equilibrium in the choice of quality and as firms are ex ante symmetric, its mirror image is also an equilibrium. As stressed above, even though firms are ex ante identical, they are ex post different, and the firm that produces the higher quality product is more profitable! Thus, we see ourselves as providing both a new model of quality and a possible reason for profits to be higher in higher quality niches! In ongoing work, we are working on extending the model to the case of many firms. We are also looking at the effects of policy in this model and comparing its predictions to those of standard models. 


\section{Appendix 1}

We proceed by establishing a series of small results which allow us to essentially construct the equilibrium strategies. For concreteness, we assume that consumers visit firm $L$ first in the event of a tie.

Lemma $11 F_{L}\left(\frac{P}{q}\right)=\frac{1}{q_{L}}-\frac{K_{L}}{q_{H} q_{L}}\left(\frac{P}{q}\right)^{-1}$.

Proof: Given that $L$ is randomizing according to $F_{L}\left(\begin{array}{l}p \\ q\end{array}\right)$, the expected profits of firm $H$ must be constant and at least $\left(1-q_{L}\right) q_{H} V$ over the support of its own distribution. Let $K_{H}$ denote the expected profits of $H$ in equilibrium so that:

$$
\begin{aligned}
E \pi_{H}\left(\frac{P_{H}}{q_{H}}\right) & =F_{L}\left(\frac{P_{H}}{q_{H}}\right)\left(1-q_{L}\right) P_{H}+\left(1-F_{L}\left(\frac{P_{H}}{q_{H}}\right)\right) P_{H} \\
& =-q_{L} P_{H} F_{L}\left(\frac{P_{H}}{q_{H}}\right)+P_{H} \\
& =K_{H}
\end{aligned}
$$

This implies that:

$$
\begin{aligned}
F_{L}\left(\frac{P_{H}}{q_{H}}\right) & =\frac{P_{H}-K_{H}}{q_{L} P_{H}} \\
& =\frac{1}{q_{L}}-\frac{K_{H}}{q_{L} P_{H}} \\
& =\frac{1}{q_{L}}-\frac{K_{H}}{q_{H} q_{L}}\left(\frac{P_{H}}{q_{H}}\right)^{-1}
\end{aligned}
$$

which completes the proof.

Lemma $12 F_{H}\left(\frac{P}{q}\right)=\frac{1}{q_{H}}-\frac{K_{L}}{q_{H} q_{L}}\left(\frac{P}{q}\right)^{-1}$.

Proof:

$$
\begin{aligned}
E \pi_{L}\left(\frac{P_{L}}{q_{L}}\right) & =F_{H}\left(\frac{P_{L}}{q_{L}}\right)\left(1-q_{H}\right) P_{L}+\left(1-F_{H}\left(\frac{P_{L}}{q_{L}}\right)\right) P_{L} \\
& =-q_{H} P_{L} F_{H}\left(\frac{P_{L}}{q_{L}}\right)+P_{L} \\
& =K_{L}
\end{aligned}
$$


Hence:

$$
\begin{aligned}
F_{H}\left(\frac{P_{L}}{q_{L}}\right) & =\frac{P_{L}-K_{L}}{q_{H} P_{L}} \\
& =\frac{1}{q_{H}}-\frac{K_{L}}{q_{H} P_{L}} \\
& =\frac{1}{q_{H}}-\frac{K_{L}}{q_{H} q_{L}}\left(\frac{P_{L}}{q_{L}}\right)^{-1}
\end{aligned}
$$

which completes the proof.

Lemma $13 V$ is the upper bound of the support of $F_{L}\left(\frac{P}{q}\right)$ and of $F_{H}\left(\frac{P}{q}\right)$

Proof: First, note that the upper bound of the support for a firm cannot exceed $V$ as this would require the firm to play a dominated strategy. Second, if the upper bound for firm $L$ were $Z<V$, then from (13),

$$
\begin{aligned}
F_{L}(Z) & =\frac{1}{q_{L}}-\frac{K_{H}}{q_{H} q_{L}}(Z)^{-1} \\
& =1
\end{aligned}
$$

Hence:

$$
K_{H}=\left(1-q_{L}\right) q_{H} Z<\left(1-q_{L}\right) q_{H} V .
$$

However, this is not possible as $H$ can always get $\left(1-q_{L}\right) q_{H} V$ by pricing at $V$. Thus, the upper bound for firm $L$ is $V$.

Similarly, if the upper bound for firm $H$ were $Z<V$, then from (14),

$$
\begin{aligned}
F_{H}(Z) & =\frac{1}{q_{H}}-\frac{K_{L}}{q_{H} q_{L}}(Z)^{-1} \\
& =1
\end{aligned}
$$

Hence:

$$
K_{L}=\left(1-q_{H}\right) q_{L} Z<\left(1-q_{H}\right) q_{L} V .
$$

However, this is not possible as $L$ can get at least $\left(1-q_{L}\right) q_{H} V$ by pricing at $V$. Thus, the upper bound cannot be less than $V$ for $L$. Hence it must be $V$.

Lemma $14\left(1-q_{L}\right) V$ is the lower bound for $F_{L}\left(\frac{P}{q}\right)$ and $F_{H}\left(\frac{P}{q}\right)$. 
Proof: Recall that the lower bounds of $H$ and $L$ must be equal and this common lower bound cannot be less than $\frac{P_{H}^{*}}{Q_{H}}=\left(1-q_{L}\right) V$ as argued in Section 2 above. Suppose this common lower bound equals $Z>\frac{P_{H}}{q_{H}}=$ $\left(1-q_{L}\right) V$. Then by pricing just below $Z$, Firm $H$, which is not the favored firm in the event of a tie, can make profits just short of $Z q_{H}$. However, as $Z q_{H}>\left(1-q_{L}\right) q_{H} V$ since $Z>\left(1-q_{L}\right) V$, these exceed the profits made at the upper bound of $V$ for this firm. Since $V$ is in the support of the mixed strategy equilibrium, $Z$ cannot be.

Lemma $15 K_{H}=\left(1-q_{L}\right) q_{H} V$.

Proof: Knowing that the upper bound of $F_{L}[$.$] is V$ allows us to solve for $K_{H}$ using (13), so that

$$
\begin{aligned}
F_{L}(V) & =\frac{1}{q_{L}}-\frac{K_{H}}{q_{H} q_{L}}(V)^{-1} \\
& =1
\end{aligned}
$$

so that

$$
K_{H}=\left(1-q_{L}\right) q_{H} V
$$

More intuitively, as Firm $H$ is always the consumer's second choice when it charges $V$, it earns profits of $\left(1-q_{L}\right) q_{H} V$ by doing so. As $V$ is in the support of its distribution, the mixed strategy must yield this level of profits in equilibrium. Hence, $K_{H}=\left(1-q_{L}\right) q_{H} V$.

Lemma $16 F_{L}\left(\frac{P}{q}\right)=\frac{1}{q_{L}}-\frac{\left(1-q_{L}\right) V}{q_{L}}\left(\frac{P}{q}\right)^{-1}$.

Proof: Substituting (18) into (13) we find:

$$
\begin{aligned}
F_{L}\left(\frac{P}{q}\right) & =\frac{1}{q_{L}}-\frac{\left(1-q_{L}\right) q_{H} V}{q_{H} q_{L}}\left(\frac{P}{q}\right)^{-1} \\
& =\frac{1}{q_{L}}-\frac{\left(1-q_{L}\right) V}{q_{L}}\left(\frac{P}{q}\right)^{-1} .
\end{aligned}
$$

Lemma $17 K_{L}=\left(1-q_{L}\right) q_{L} V$.

Proof: Firm $L$ is always the lower priced firm when it prices at $\left(1-q_{L}\right) V$, which is in its support. By doing so it earns profits of $\left(1-q_{L}\right) q_{L} V$. Hence:

$$
K_{L}=\left(1-q_{L}\right) q_{L} V
$$


Lemma $18 F_{H}\left(\frac{P}{q}\right)=\frac{1}{q_{H}}-\frac{\left(1-q_{H}\right) V}{q_{H}}\left(\frac{P}{q}\right)^{-1}$.

Proof: Comes from substituting for $K_{L}$ from (20)into (14) to get;

$$
\begin{aligned}
F_{H}\left(\frac{P}{q}\right) & =\frac{1}{q_{H}}-\frac{\left(1-q_{L}\right) q_{L} V}{q_{H} q_{L}}\left(\frac{P}{q}\right)^{-1} \\
& =\frac{1}{q_{H}}-\frac{\left(1-q_{L}\right) V}{q_{H}}\left(\frac{P}{q}\right)^{-1}
\end{aligned}
$$

Lemma $19 F_{H}\left(\frac{P}{q}\right)$ has a mass point at $V$ of $\left(1-\frac{q_{L}}{q_{H}}\right)$.

Proof: Evaluating $F_{H}\left(\frac{P}{q}\right)$ at $\frac{P}{q}=V$ yields:

$$
\begin{aligned}
F_{H}(V) & =\frac{1}{q_{H}}-\frac{\left(1-q_{L}\right) V}{q_{H} V} \\
& =\frac{q_{L}}{q_{H}} \\
& <1 .
\end{aligned}
$$

This indicates that Firm $H$ chooses $V$ with probability $\left(1-\frac{g_{L}}{q_{H}}\right)$.

Now we must verify that mixing is an optimal response for Firm $L$, i.e. expected profits are constant over the support of Firm $H$ 's mixed strategy and there are no other strategies outside the support which yield a higher expected profit to Firm $L$. This is done in the text in Section 2. 
Table 1

Product Quality and its Effect on Profitability PIMS Data Base

Return on Investment and Net Profit as a Percentage of Sales, by Strategic Position

Quality Relative to Competitors

Low Average High

Return on Investment

$13 \quad 17-21 \quad 30$

Net Profit as a Percentage of Sales $6 \quad 8-9 \quad 14$

Source: Robert D. Buzzell, "Product Quality", The PIMS letter on Business Strategy, No. 4, 1978. 
Table 2

Return on Investment, by Strategic Position

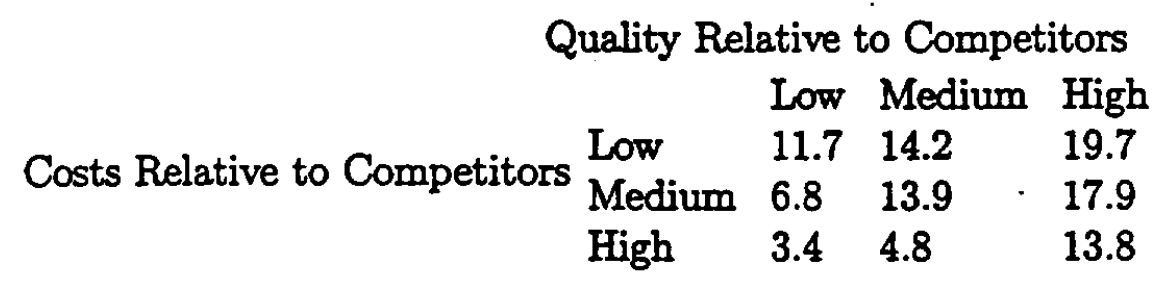

Source: J. Kay, Financial Times (10 May 1996) p. 17. 
Table 3

Summary of Notation from Section 3

$q \quad$ The profit maximizing quality choice of Firm $L$.

$\underline{-} \underline{L} \quad$ The maximum profits of the low quality producer.

$\bar{q}_{L}^{L} \quad$ Firm $L ' s$ choice which equates the two firms' profits with concave costs.

$q_{H}\left(q_{L}\right)$ Firm $H^{\prime}$ s best response function.

Firm $L$ 's choice which elicits the best response from Firm $H$

$\hat{q}_{L} \quad$ which equates the two firms' profits with convex costs.

$q_{L}^{c} \quad$ Firm $L$ 's choice which induces Firm $H$ to also choose $q_{L}^{c}$. 
Bibliography

\section{References}

[1] Buzzell, Robert D. (1978) "Product Quality", The PIMS letter on Business Strategy, No. 4.

[2] Buzzell, Robert D. and Fredrick D. Wiersema (1981) "Successful ShareBuilding Strategies". Harvard Business Review, January-February, pp. 135-144.

[3] Darlin, Damon (1985) "Although U.S. Cars are Improved, Imports still Win Quality Survey" Wall Street Journal, December 16th, p. 29.

[4] Kay, J. (1996) Financial Times, May 10th, p. 17.

[5] Main, Jeremy. "The Battle for Quality Begins", Fortune, December 29, 1980, p. 33.

[6] Mussa, M. and S. Rosen (1978). "Monopoly and Product Quality," Journal of Economic Theory, Vol. 18, No. 2, pp. 301-317.

[7] Peters, Thomas J. and Robert H. Waterson, Jr. (1982). "In Search of Excellence: Lessons from America's Best Run Companies". New York: Harper and Row.

[8] Porter, Michael E. (1980) "Competitive Strategies: Techniques for Analyzing Industries and Companies". New York: The Free Press, pp. 37-38.

[9] Shaked, Avner and John Sutton. (1983). "Natural Oligopolies", Econometrica, Volume 51, No. 5, pp. 1469-1484.

[10] Shaked, Avner and John Sutton. (1982). "Relaxing Price Competition through product Differentiation", Review of Economic Studies, Volume 49, No. 1, pp. 3-14.

[11] Sheshinski, Eytan. (1976). "Price, Quality and Quantity Regulation in Monopoly Situations", Economica, Vol. 43, pp. 127-138. 
Table 3

Summary of Notation from Section 3

$q \quad$ The profit maximizing quality choice of Firm $L$.

$I_{L} L$ The maximum profits of the low quality producer.

$\overline{\bar{q}}_{L}^{L} \quad$ Firm $L$ 's choice which equates the two firms' profits with concave costs.

$q_{H}\left(q_{L}\right)$ Firm $H^{\prime}$ 's best response function.

$\hat{q}_{L} \quad$ Firm $L$ 's choice which elicits the best response from Firm $H$

$q_{L} \quad$ which equates the two firms' profits with convex costs.

$q_{L}^{c} \quad$ Firm $L$ 's choice which induces Firm $H$ to also choose $q_{L}^{c}$. 


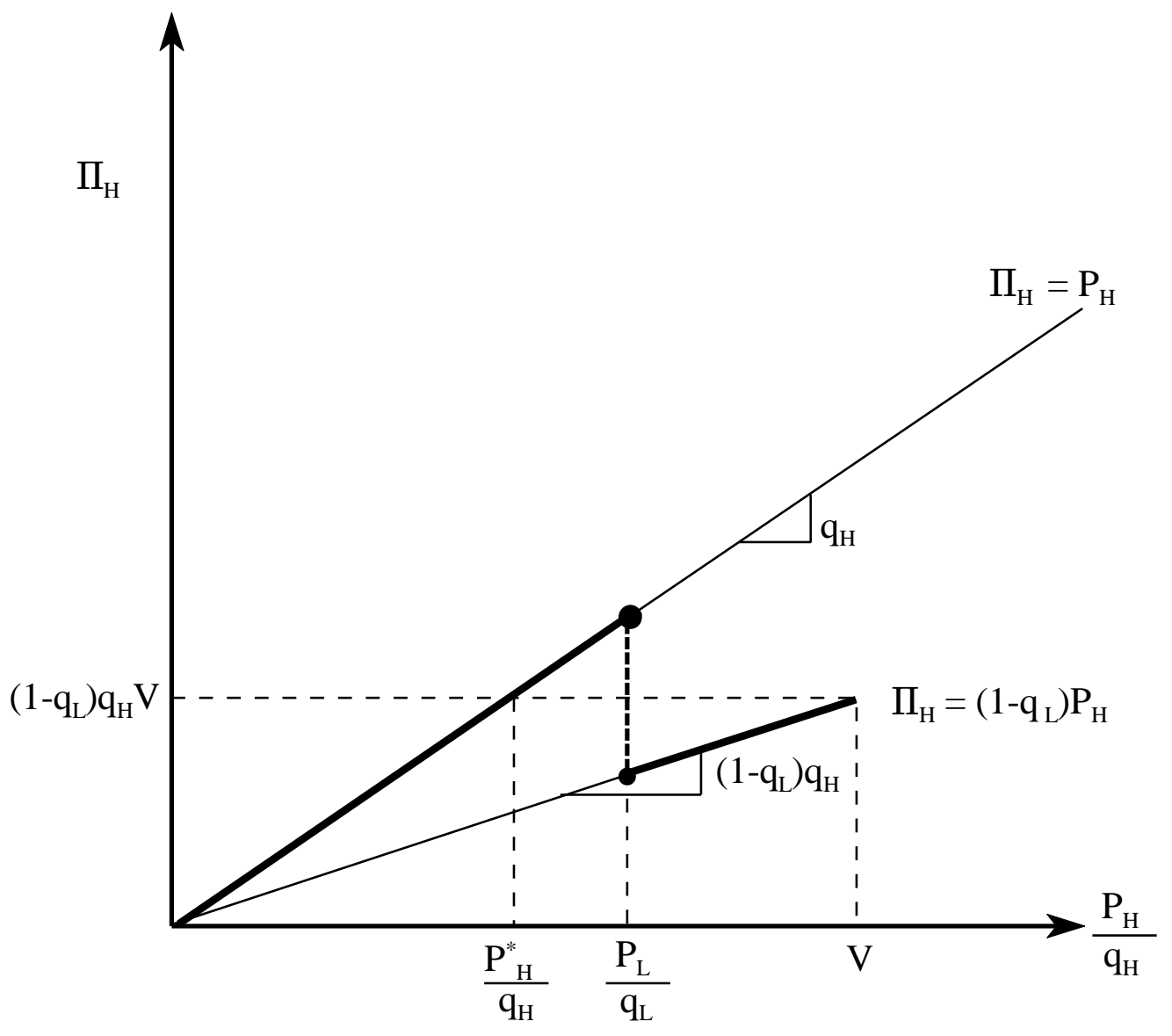

Profits of Firm $\mathrm{H}$

Figure 1 


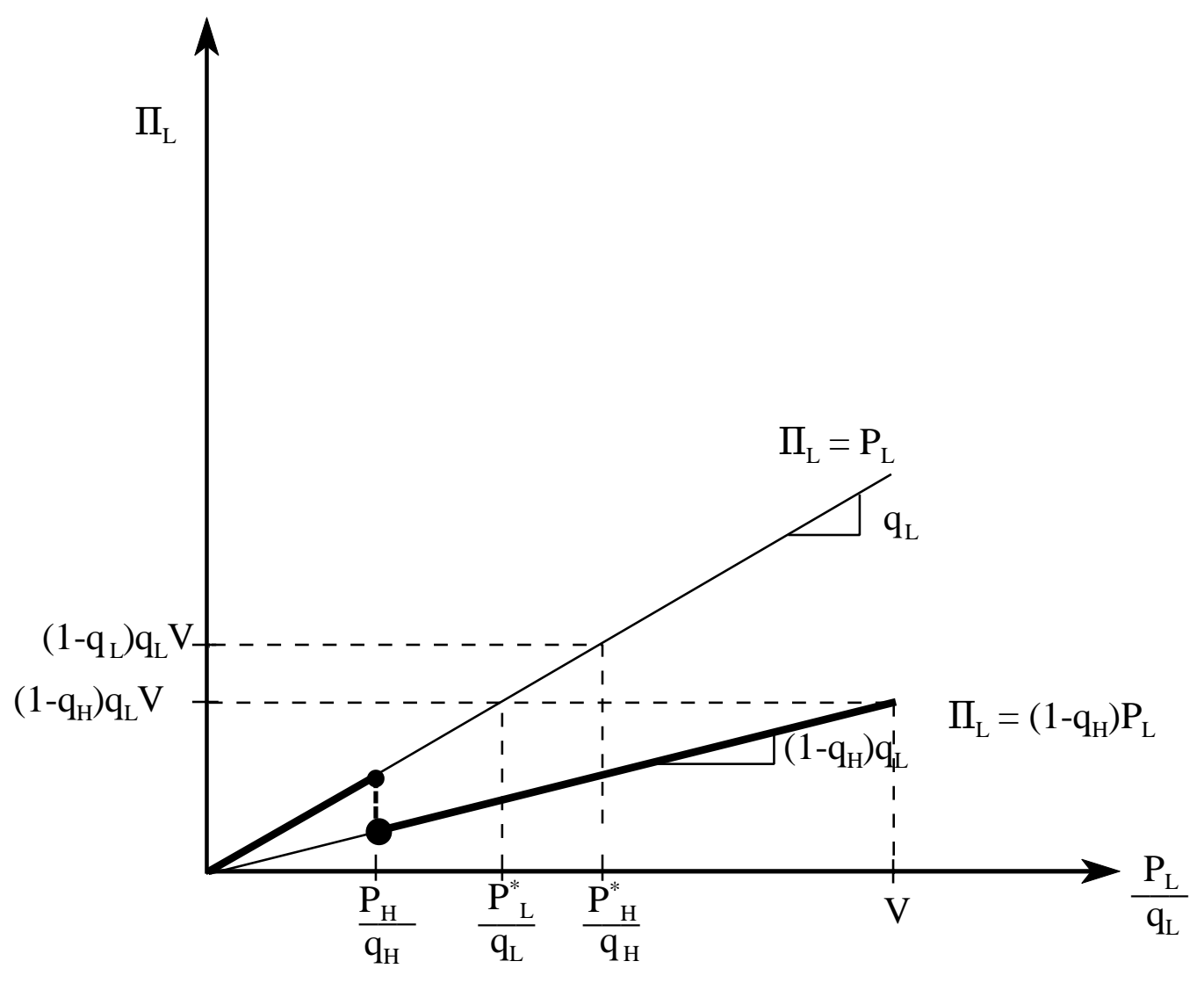

Profits of Firm L

Figure 2 


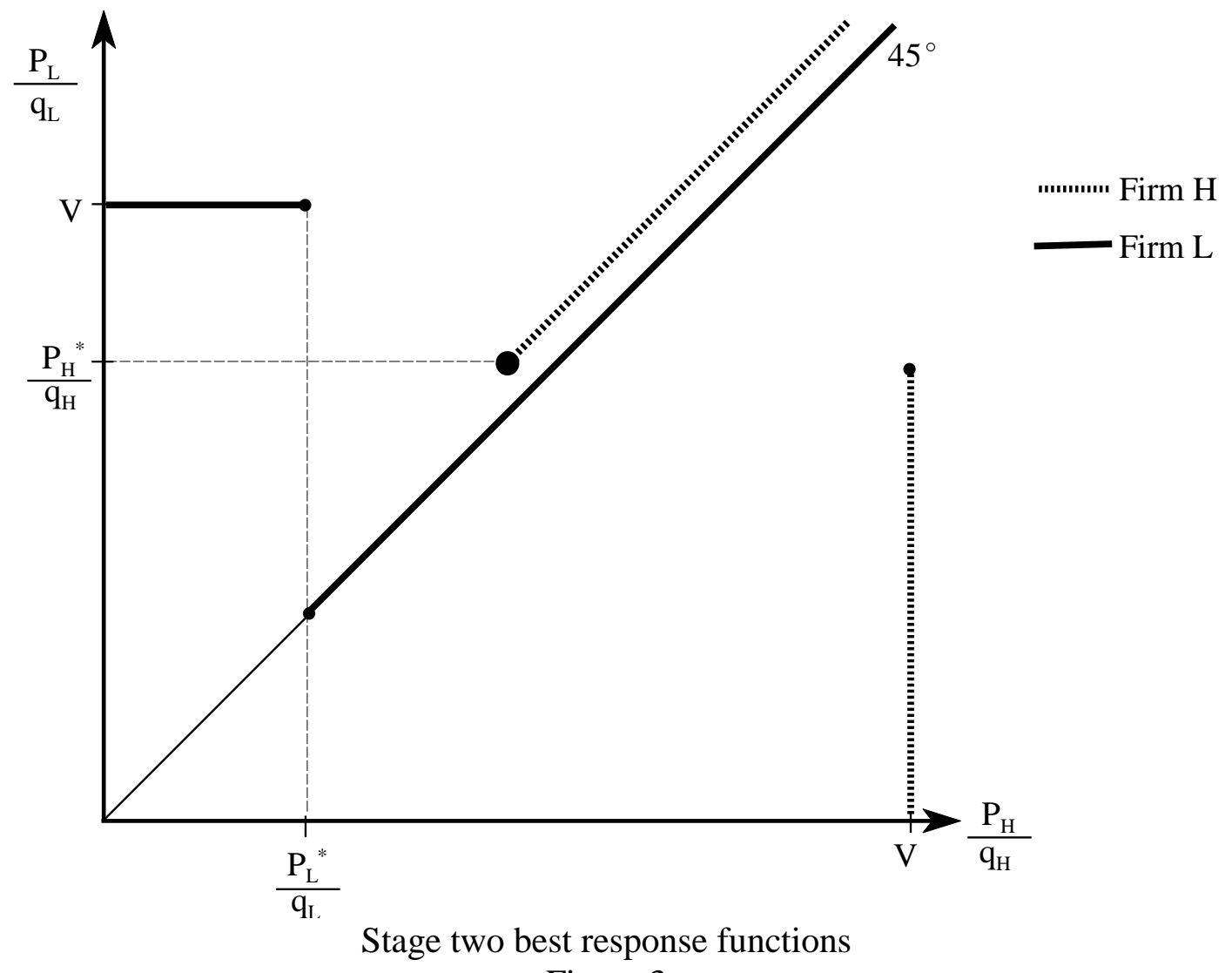

Figure 3 


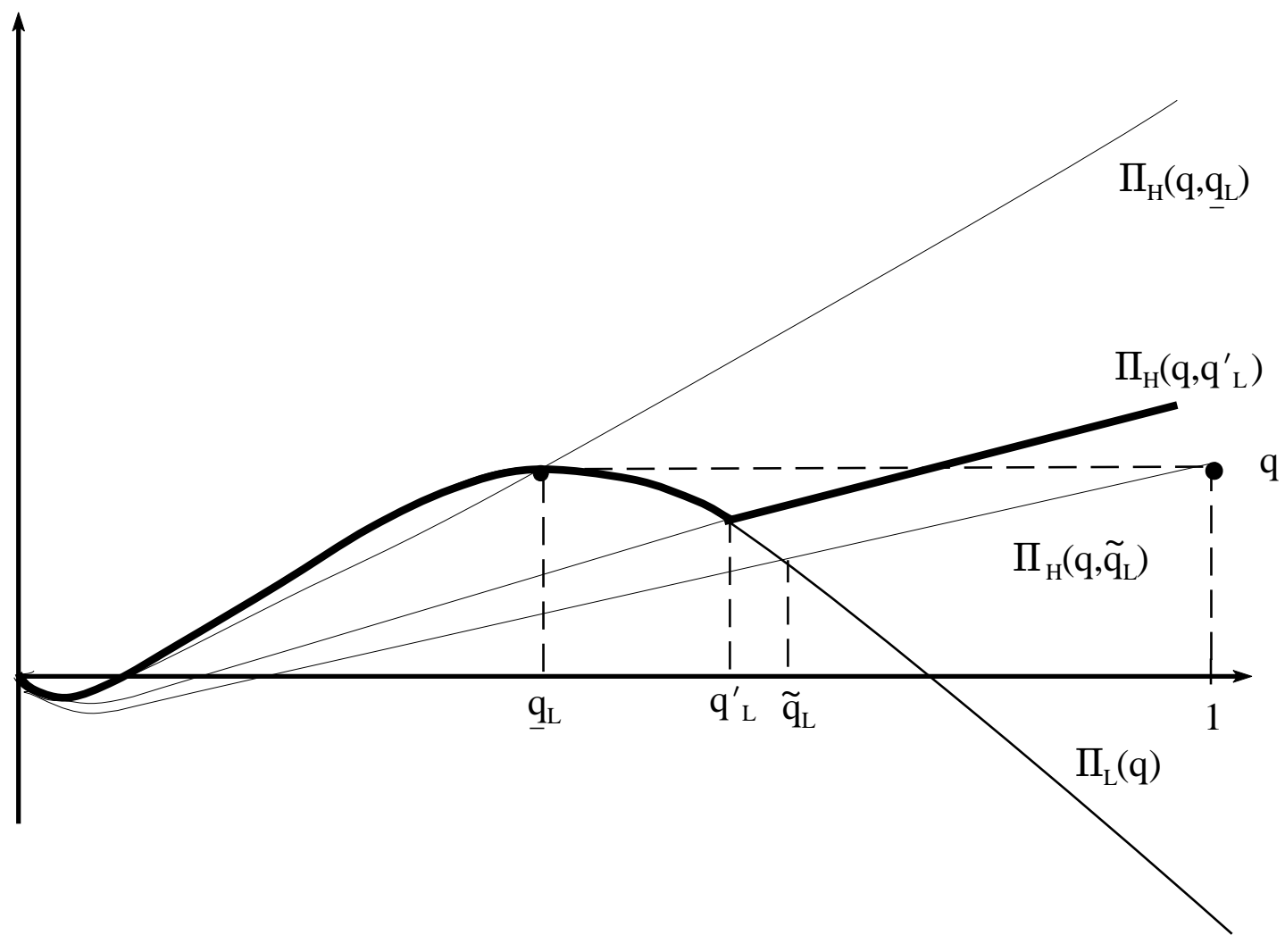

Profits with concave costs of quality

Figure 4 


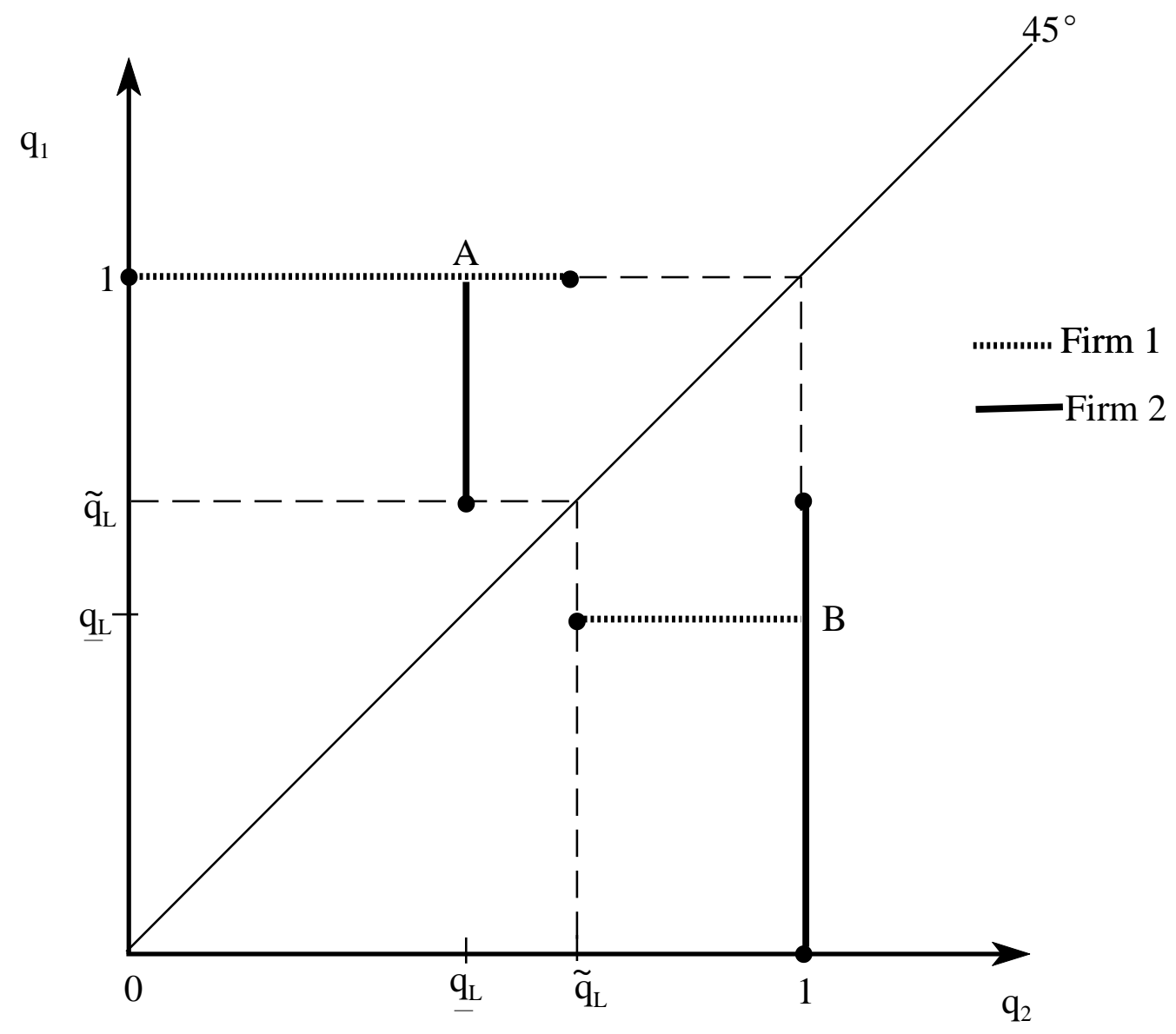

Equilibrium quality choices with concave costs of quality Figure 5 


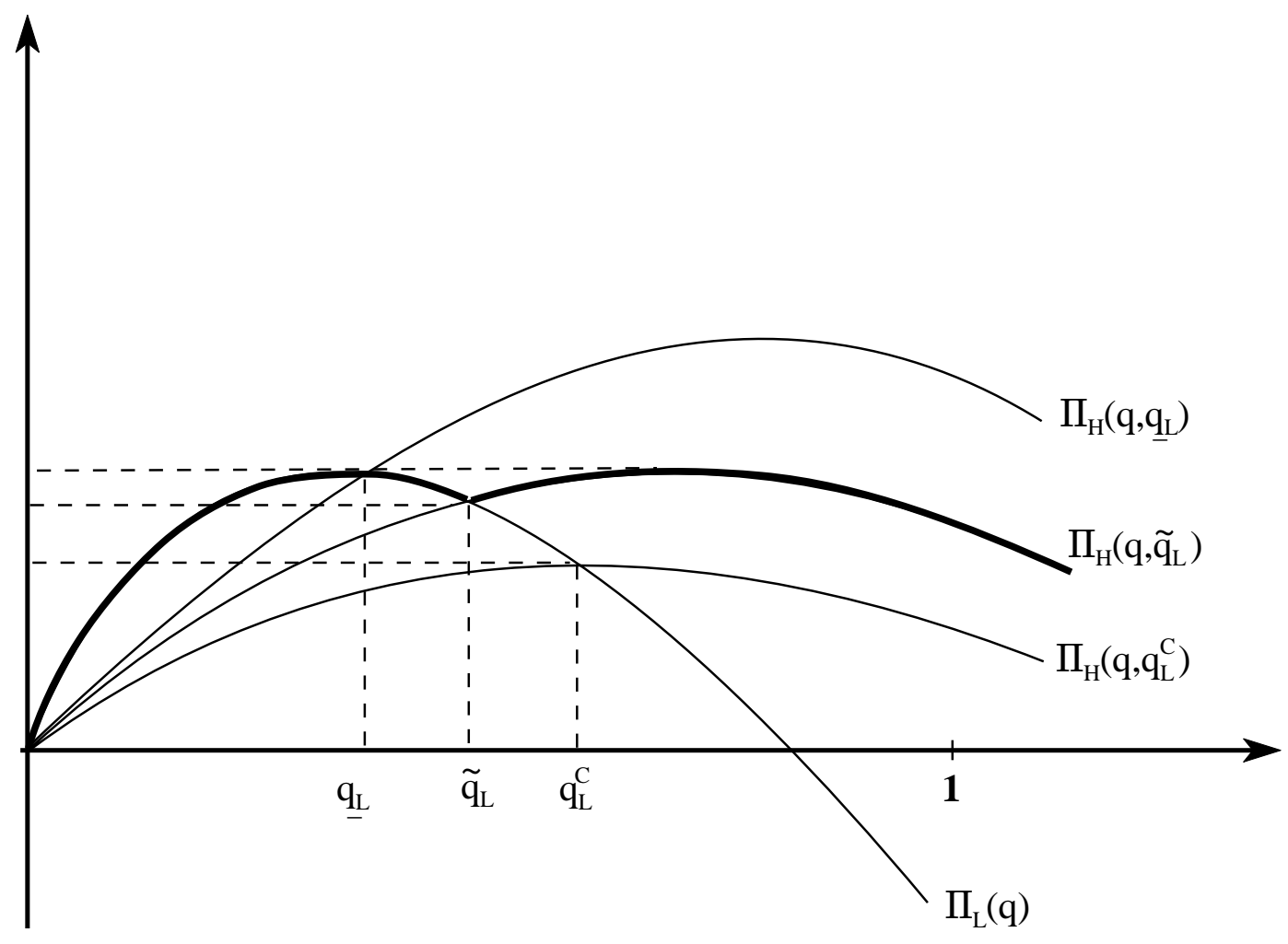

Profits with convex costs of quality

Figure 6 


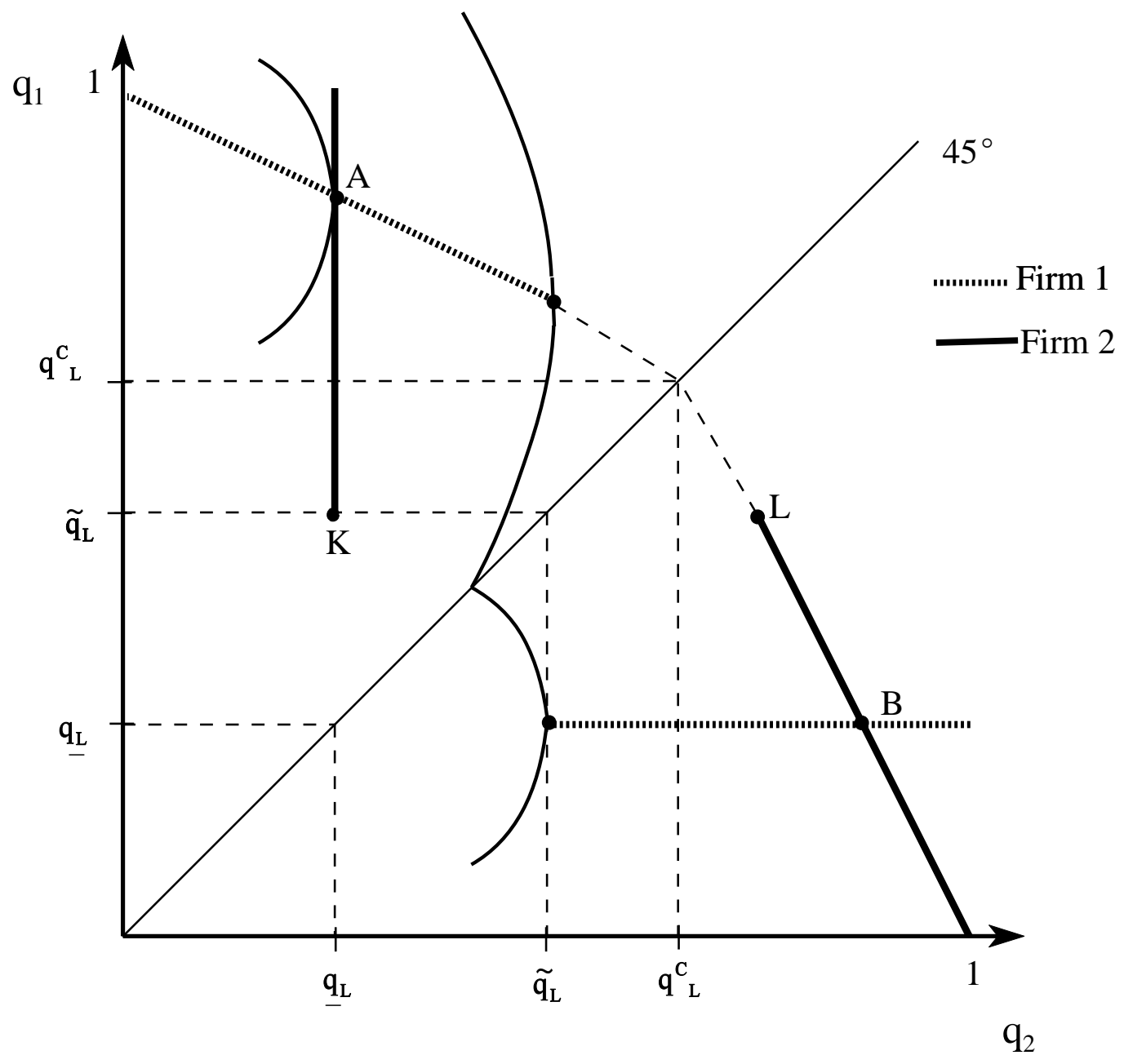

Quality choices with convex costs of quality

Figure 7 